\title{
PEMBERDAYAAN PEMANFAATAN LIMBAH TANAMAN BUNGA KRISAN DI DESA CANDI KECAMATAN BANDUNGAN KABUPATEN SEMARANG
}

\author{
Empowerment of utilization the Chrysanthemum Plant Waste in Candi \\ Village, Bandungan District Semarang Regency
}

\author{
Agus Santosa, Siti Hamidah*, Budiarto \\ Program Studi Agribisnis Fakultas Pertanian \\ Universitas Pembangunan Nasional "Veteran" Yogyakarta \\ Jl. Padjajaran 104, Kecamatan Depok, Kabupaten Sleman, Yogyakarta \\ email korespondensi : shamidah81@yahoo.co.id
}

Diterima tanggal : 21 September 2019 ; Disetujui tanggal : 29 November 2019

\begin{abstract}
This study aims to examine the implementation of the empowerment program for the utilization of chrysanthemum flower waste in Candi Village, Bandungan District, Semarang Regency. This research use descriptive qualitative approach. The technique of determining respondents was done by using purposive sampling method. The data source used was primary data. Data collection techniques used were observation, interviews and documentation methods. The assessment was carried out by observing and analyzing the stages of the empowerment process and the results achieved (impact). The results of the study showed that the implementation of the empowerment program for the utilization of chrysanthemum flower waste in Candi Village, Bandungan District, Semarang Regency had been going well with the stages, namely (1) the empowerment program was carried out through the formation of the Women Farmers Group (KWT), socialization, training, mentoring, monitoring and evaluation, (2) KWT members of Mitra Veteran Mandiri have been able to utilize the waste of Chrysanthemum plants into processed products that have economic value, namely Tea, Rempeyek / Chrysanthemum and Chrysanthemum Candy, (3) KWT Mitra Veteran Mandiri members have been able to transmit their skills to other community, and students of Agriculture Faculty, UPN "Veteran" Yogyakarta. The process of empowering the community by utilizing the results and waste from locally cultivated plants should be continued, in order to improve the welfare of the community.
\end{abstract}

Keywords : Chrysanthemum Waste Processed Products, Empowerment, Skill

\begin{abstract}
ABSTRAK
Penelitian ini bertujuan mengkaji pelaksanaan program pemberdayaan pemanfaatan limbah tanaman bunga krisan di Desa Candi Kecamatan Bandungan Kabupaten Semarang. Penelitian ini menggunakan pendekatan deskriptif kualitatif dengan teknik penentuan responden dilakukan secara purposive sampling. Sumber data yang digunakan adalah data primer yang teknik pengumpulan data dilakukan
\end{abstract}


dengan menggunakan teknik observasi, wawancara dan dokumentasi. Pengkajian dilaksanakan dengan cara mengamati dan menganalisis tahap-tahap proses pemberdayaan dan hasil yang dicapai (dampak). Hasil kajian menunjukkan bahwa pelaksanaan program pemberdayaan pemanfaatan limbah tanaman bunga krisan di Desa Candi Kecamatan Bandungan Kabupaten Semarang sudah berjalan dengan baik dengan tahap-tahapan yaitu (1) program pemberdayaan dilaksanaan melalui pembentukan Kelompok Wanita Tani (KWT), sosialisasi, pelatihan, pendampingan, monitoring dan evaluasi, (2) anggota KWT Mitra Veteran Mandiri sudah mampu memanfaatkan limbah tanaman bunga Krisan menjadi produk olahan yang mempunyai nilai ekonomis, yaitu Teh, Rempeyek/ Kripik dan Permen Krisan, (3) anggota KWT Mitra Veteran Mandiri sudah mampu menularkan ketrampilannya kepada anggota masyarakat yang lebih luas, dan mahasiswa Fakultas Pertanian UPN "Veteran" Yogyakarta. Proses Pemberdayaan kepada Masyarakat dengan memanfaatkan hasil maupun limbah dari tanaman lokal yang banyak dibudidayakan sebaiknya dilanjutkan, guna meningkatkan kesejahteraan masyarakat.

Kata Kunci: Produk Olahan Limbah Krisan, Pemberdayaan, Keterampilan

\section{PENDAHULUAN}

Krisan merupakan salah satu bunga potong maupun tanaman pot yang paling populer pada perdagangan internasional. Pada masa kini krisan menempati 10 besar tanaman hias populer yang dipasarkan oleh lebih dari 150 negara (Handajaningsih \& Wibisono 2009). Bunga krisan memiliki berbagai keunggulan, di antaranya mempunyai karakter tidak mudah layu serta variasi warna dan bentuk bunga sangat beragam dibandingkan dengan bunga lain. Dari segi keunggulan usahatani, tanaman krisan mudah dibudidayakan, umur panen relatif pendek, bunga dapat dipanen serentak, waktu pembungaan, dan waktu panen dapat diatur sesuai kebutuhan pasar, misalnya ketika permintaan tinggi pada hari-hari besar nasional keagamaan, hari kemerdekaan, musim pernikahan, dan perayaan lainnya.

Tanaman Krisan selama ini hanya dikenal sebagai tanaman yang menghasilkan bunga potong, dimana pemanfaatan sebatas pada bagian bunga dan tangkai. Dari beberapa penelitian menunjukkan bahwa tanaman Krisan memiliki beberapa kelebihan karena kandungan zat aktif pada bagian daun dan bunga. Bunga Krisan mengandung flavanoid berupa quercitrin, myricetin, dan luteolin 7glukosida yang memiliki efek farmakologis. Selain itu bunga dan daun krisan memiliki aroma yang sangat kuat dan beberapa penelitian menunjukkan kandungan 
esensial oil pada bunga bunga Krisan (Shen et al., 2004; Wang et al., 2006; Ye et al., 2009).

Tanaman krisan saat ini baru dimanfaatkan sebagai bunga potong, belum memanfaatkan daun dan bunga yang tidak lolos sortasi, sehingga hanya sebagai limbah. Melihat nilai fungsional yang terkandung dalam daun dan bunga Krisan, maka diperlukan introduksi teknologi diversifikasi pengolahan Krisan. Diversifikassi pengolahan ini dilakukan menggunakan bahan-bahan yang mudah didapat karena hanya sebagai limbah serta peralatan yang digunakan adalah peralatan rumah tangga. Agar limbah tanaman bunga krisan yang berupa daun dan bunga yang tidak lolos sortasi pada kelompok tani Mitra Veteran Mandiri khususnya dan di Kecamatan Bandungan pada umumnya dapat dimanfaatkan dan bernilai ekonomis, perlu bantuan untuk melakukan diversifikasi pengolahan krisan. Oleh karena itu, telah dilaksanakan Program Pengabdian bagi Masyarakat ( $\mathrm{PbM})$ oleh Dosen Fakultas Pertanian UPN "Veteran" Yogyakarta pada bulan Mei Oktober 2019.

Berdasarkan uraian sebelumnya, maka perlu dilakukan pengkajian terhadap pelaksanaan program pemberdayaan pemanfaatan limbah tanaman bunga krisan di Desa Candi Kecamatan Bandungan Kabupaten Semarang, hasil serta dampaknya bagi masyarakat sekitarnya.

\section{METODE PENELITIAN}

Penelitian ini menggunakan pendekatan deskriptif kualitatif dengan teknik penentuan responden dilakukan secara purposive sampling yaitu anggota kelompok tani Mitra Veteran Mandiri di Desa Candi, Kecamatan Bandungan, Kabupaten Semarang. Sumber data yang digunakan adalah data primer yaitu data yang diambul dengan teknik pengumpulan data menggunakan teknik observasi, wawancara dan dokumentasi. Pengkajian dilaksanakan dengan cara mengamati dan menganalisis tahap-tahap proses pemberdayaan dan hasil yang dicapai (dampak). Pengkajian dilaksanakan dengan cara mengamati dan menganalisis tahap-tahap proses pemberdayaan, hasil yang dicapai dan dampaknya bagi masyarakat sekitarnya. 


\section{HASIL DAN PEMBAHASAN}

\section{Tahap-tahap Proses Pemberdayaan}

Pelaksanaan program pemberdayaan "Pemanfaatan Limbah Tanaman Bunga Krisan kepada KWT Mitra Veteran Mandiri” secara terinci dapat dilihat pada Tabel 1. Secara umum pelaksanaan program pemberdayaan kepada anggota KWT Mitra Veteran Mandiri berjalan lancar, melalui beberapa tahapan. Tahapan pertama yaitu dengan membentuk kelompok wanita tani yang bernama KWT Mitra Veteran Mandiri, yang beranggotakan Ibu-ibu (isteri Bapak-bapak anggota KT Mitra Veteran Mandiri). Transfer ilmu, pengetahuan dan teknologi kepada anggota KWT Mitra Veteran Mandiri telah dilaksanakan pendekatan pada tiga ranah, yaitu kognitif, afektif dan psikomotorik.

Para anggota KWT Mitra Veteran Mandiri yang beranggota ibu-ibu warga Desa Candi Kecamatan Bandungan Kabupaten Semarang mengetahui pemanfaatan limbah tanaman bunga krisan melalui sosialisasi kandungan antioksidan dalam tanaman bunga krisan dan limbah tanaman bunga krisan tersebut dapat diolah menjadi produk yang punya nilai ekonomis dengan menggunakan cara, alat dan tambahan bahan lain. Ibu-ibu yang tertarik dengan ide pemanfaatan limbah bunga krisan kemudian mengikuti pelatihan untuk menambah ketrampilan dalam mengolah limbah tanaman bunga krisan menjadi produk teh, keripik dan permen krisan.

Setelah mendapatakan pelatihan, anggota KWT Mitra Veteran Mandiri berlatih dan berusaha melakukan secara rutin uji coba pembuatan produk turunan krisan, namun masih dalam jumlah relatif sedikit. Masukan dari tim $\mathrm{PbM}$ dan Bapak-bapak anggota KT Mitra Veteran Mandiri, didengarkan dan dijadikan kritik dan saran sebagai perbaikan produk misalnya bahwa tektur terlalu kering, rasa terlalu asin atau kurang manis dan warna kurang menarik. Selanjutnya akan dijadikan umpan balik untuk melakukan proses pengolahan dengan lebih baik dan teliti. Walapun sudah dapat memproduksi produk olahan dari limbah tanaman bunga krisan, namun ibu-ibu anggota KWT Mitra Veteran Mandiri belum berani menjual hasil olahan limbah tanaman krisan tersebut. 
Tabel 1. Tahap-Tahap Proses Pemberdayaan Pemanfaatan Limbah Tanaman Bunga Krisan Pada KWT Mitra Veteran Mandiri

\begin{tabular}{|c|c|c|c|c|c|}
\hline Kegiatan & Tujuan & Metode & Sasaran & Waktu & Hasil \\
\hline Sosialisasi Program & $\begin{array}{l}\text { Mengenalkan kualitas dan } \\
\text { komponen antioksidan } \\
\text { tanaman krisan }\end{array}$ & $\begin{array}{l}\text { Ceramah dan } \\
\text { Tanya jawab }\end{array}$ & KWT & $\begin{array}{l}\text { Sabtu, } 27 \text { April } \\
2019 \text { dan } \\
\text { Kamis, } 27 \text { Juni } \\
2019\end{array}$ & $\begin{array}{l}\text { Sudah dilaksanakan,lancar tanpa } \\
\text { halangan }\end{array}$ \\
\hline $\begin{array}{l}\text { Pelatihan olahan daun } \\
\text { dan bunga krisan }\end{array}$ & $\begin{array}{l}\text { Menambah ketrampilan } \\
\text { membuat olahan daun dan } \\
\text { bunga krisan menjadi teh, } \\
\text { rempeyek/keripik dan permen }\end{array}$ & $\begin{array}{l}\text { Workshop dan } \\
\text { Pelatihan }\end{array}$ & KWT & $\begin{array}{l}\text { Senin, } 22 \text { Juli } \\
2019\end{array}$ & $\begin{array}{l}\text { Sudah dilaksanakan. } \\
\text { Anggota KWT sangat antusias }\end{array}$ \\
\hline $\begin{array}{l}\text { Pendampingan } \\
\text { pengelolaan usaha }\end{array}$ & $\begin{array}{l}\text { Menambah ketrampilan dalam } \\
\text { mengelola usaha olahan daun } \\
\text { dan bunga krisan }\end{array}$ & Pendampingan & KWT & $\begin{array}{l}\text { Sabtu, } 11 \\
\text { Agustus } 2019\end{array}$ & $\begin{array}{l}\text { Sudah dilaksanakan } \\
\text { Rutin, hasil cukup baik }\end{array}$ \\
\hline $\begin{array}{l}\text { Pendampingan design } \\
\text { kemasan }\end{array}$ & $\begin{array}{l}\text { Mengemas produk olahan } \\
\text { limbah bunga krisan agar } \\
\text { diterima pasar }\end{array}$ & Pendampingan & KWT & $\begin{array}{l}\text { Kamis, } 29 \\
\text { Agustus } 2019\end{array}$ & $\begin{array}{l}\text { Sudah dilaksanakan, } \\
\text { Hasil cukup baik }\end{array}$ \\
\hline Monitoring dan Evaluasi & $\begin{array}{l}\text { Usaha olahan bunga krisan } \\
\text { yang berkelanjutan }\end{array}$ & $\begin{array}{l}\text { Pelatihan dan } \\
\text { praktek } \\
\text { langsung }\end{array}$ & KWT & $\begin{array}{l}\text { Setiap kegiatan } \\
\text { dan selesai } \\
\text { kegiatan }\end{array}$ & $\begin{array}{l}\text { Sudah dilaksanakan,Hasil } \\
\text { semakin baik } \\
\text { Anggota KWT mampu } \\
\text { menularkan kepada anggota } \\
\text { masyarakat sekitarnya dan } \\
\text { mahasiswa FP UPNVY }\end{array}$ \\
\hline
\end{tabular}

Sumber : Analisis Data Primer (2019) 
Santosa et.al. / Jurnal Dinamika Sosial Ekonomi Vol.20 No.2, Desember 2019

\section{Pelatihan Olahan Daun dan Bunga Krisan}

Tanaman Krisan selama ini hanya dikenal sebagai tanaman yang menghasilkan bunga potong, dimana pemanfaatan sebatas pada bagian bunga dan tangkai. Balai Pengkajian Teknologi Pertanian Yogyakarta (BPTP) mengembangkan manfaat krisan menjadi teh krisan, keripik krisan, permen dan penghasil racun serangga (hama). Krisan (Chrysanthemum indicum L.) telah diketahui dan digunakan sebagai teh herbal di Thailand dan Tiongkok. Bahkan tanaman ini telah terkenal sebagai tanaman yang bermanfaat dalam menjaga kesehatan, seperti teh bunga krisan.

Teh Krisan dapat diolah dari bagian daun dan bunga. Warna bunga yang digunakan menentukan warna teh yang dihasilkan. Jika teh berasal dari bunga Krisan yang berwarna kuning seperti varietas Cintamani akan menghasilkan seduhan teh berwarna kekuningan. Jika dari bunga yang berwarna ungu akan menghasilkan warna seduhan yang keunguan. Ini merupakan salah satu keunggulan dari teh bunga Krisan (Madhavi, 1996). Daun krisan mengandung katekin. Katekin merupakan senyawa yang biasanya ada dalam teh hijau yang terkandung dalam tanin dan merupakan turunan dari asam galat (Wanita, dkk. 2015). Katekin menentukan sifat teh krisan seperti rasa, warna, dan aroma. Diduga kandungan katekin pada teh Krisan tidak terlalu besar, hal ini terlihat dari warna seduhan teh yang tidak terlalu pekat. Semakin besar kandungan katekin (tanin) pada teh, maka warna yang dihasilkan semakin pekat (coklat).
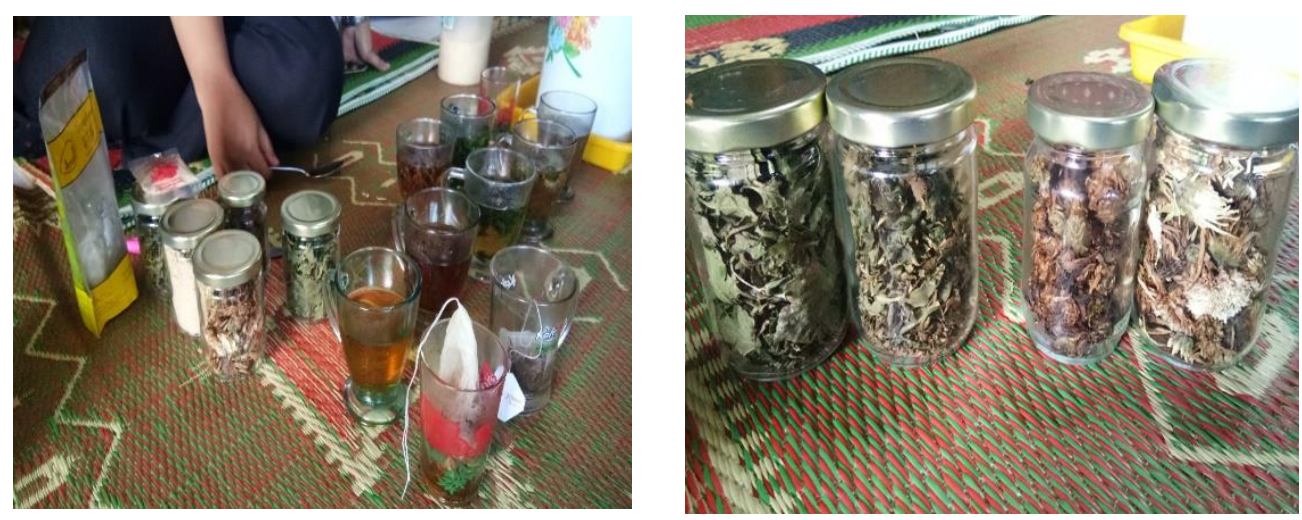

Gambar 1. Produk Minuman Teh dari Limbah Bunga dan Daun Krisan 
Teh krisan punya banyak khasiat karena dapat menjaga sistem kekebalan tubuh, mengatasi berbagai penyakit yang disebabkan infeksi bakteri, menurunkan suhu tubuh, menjaga kesehatan kulit, mengatasi aterosklerosis, menurukan kolesterol, meningkatkan fungsi otak, meredakan batuk, sakit kepala, sakit gigi ringan, dan lain sebagainya. Teh krisan dihargai tidak hanya untuk sifat obat, tetapi juga karena rasa yang unik, bunga dan daya tarik visual. Dalam pengobatan tradisional Cina teh ini dikenal dengan nama jua hua cha yang digunakan untuk mengobati berbagai penyakit, termasuk demam dan sakit tenggorokan karena memiliki efek mendinginkan. Krisan teh mengandung alkaloid seperti glikosida dan seskuiterpen. Flavonoid yang bermanfaat, termasuk cosmosin, diosmetin dan apigenin, kolin dan kamper. Teh krisan juga mengandung tiamin dan antioksidan vitamin A. Memorial Sloan-Kettering Cancer Center melaporkan bahwa teh krisan memiliki anti-inflamasi, antibakteri, antikanker dan antipiretik, atau demam penurun, sifat, serta kemampuan untuk meningkatkan aliran darah ke jantung.

Berdasarkan uraian khasiat teh krisan tersebut memunculkan ide untuk memberikan pelatihan pembuatan teh herbal yang berbahan baku daun dan bunga krisan yang terlihat pada gambar 1. Selain teh masyarakat juga diberikan tambah keterampilan dengan pelatihan pembuatan olahan daun dan bunga krisan menjadi rempeyek/keripik dan permen (gambar 2).
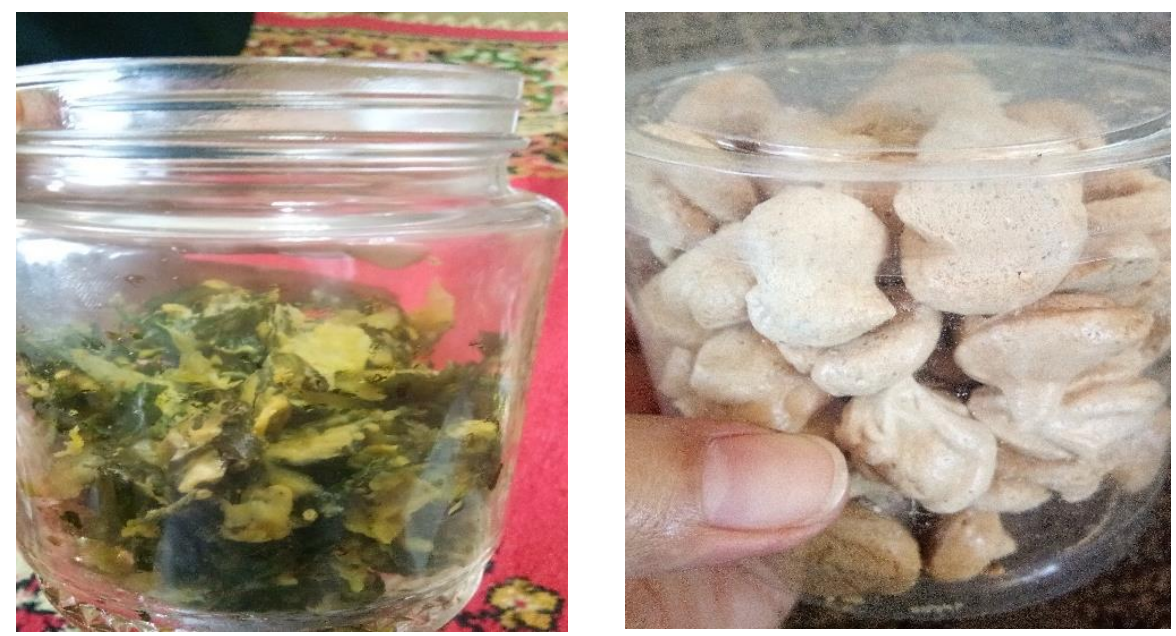

Gambar 2. Produk Camilan dari Limbah Daun Krisan (a) Keripik Daun Kripik Krisan (b) Permen Daun Krisan 
Santosa et.al. / Jurnal Dinamika Sosial Ekonomi Vol.20 No.2, Desember 2019

Monitoring dan Evaluasi Proses Pemberdayaan Pemanfaatan Limbah Tanaman Bunga Krisan Pada KWT Mitra Veteran Mandiri

Berdasarkan tahapan-tahapan yang telah dilaksanakan dalam proses pemberdayaan pemanfataan limbah tanaman bunga krisan dilakukan monitoring dan evaluasi yang kemudian diperoleh hasil yang baik. Hasil menunjukan bahwa anggota KWT Mitra Veteran Mandiri sudah mempraktekan hasil pelatihan yang didapatkan berupa pengolahan limbah tanaman krisan menjadi beberapa produk makanan sehingga memiliki nilai manfaat dan harga jual yang bersaing.
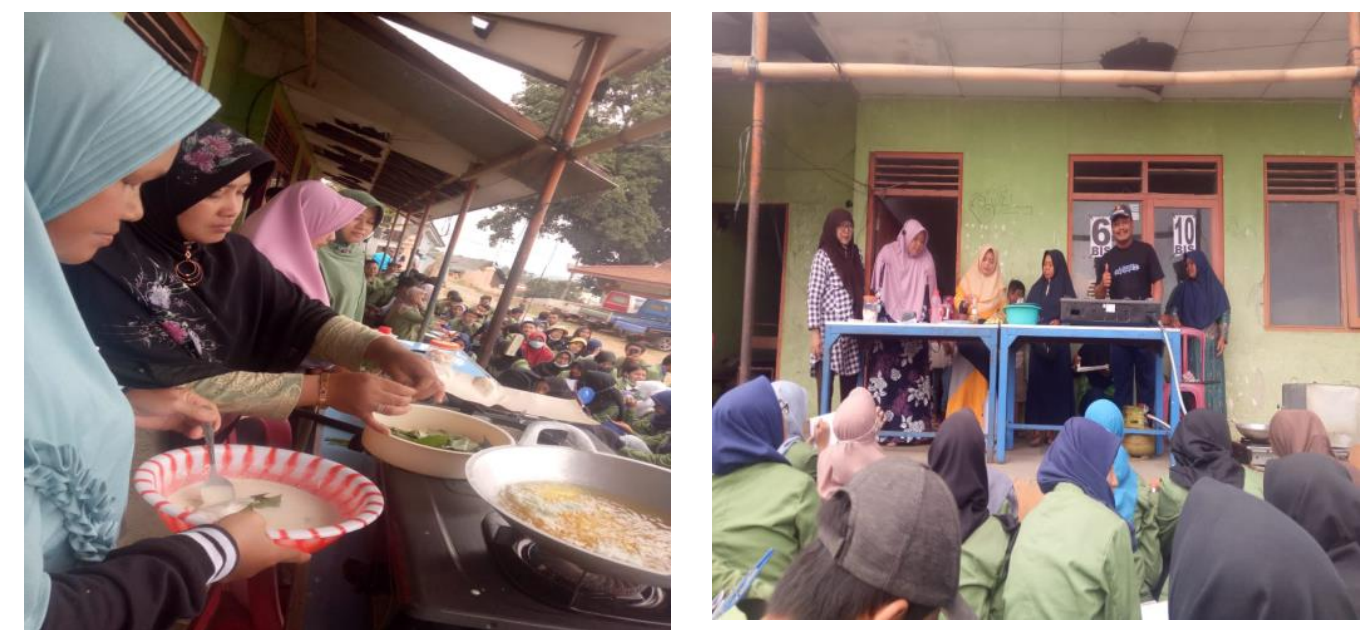

Gambar 3. KWT Mitra Veteran Mandiri mengajari pengolahan limbah krisan kepada mahasiswa Fakultas Pertanian UPN "Veteran" Yogyakarta

Dampak positif yang terjadi adalah anggota KWT Mitra Veteran Mandiri sudah mampu menularkan ketrampilannya kepada anggota masyarakat yang lebih luas salah satunya kepada mahasiswa Fakultas Pertanian UPN "Veteran" Yogyakarta. Penyaluran pemberian informasi dan praktik pengolahan limbah tanaman krisan kepada mahasiswa UPN Veteran Yogyakarta dilakukan pada saat pelaksanaan praktik lapang Pengenalan Pertanian yang diselenggarakan di Kecamatan Bandungan (Gambar 3). Kegiatan dilakukan secara berkelompok (4-5 orang) menekuni satu macam olahan limbah tanaman bunga krisan, maupun tanaman bunga yang lain, yaitu Mawar dan Dahlia. Saat menularkan dengan melakukan demo pengolahan aneka limbah tanaman bunga, ada empat macam 
olahan, yaitu : keripik daun bunga Dahlia, Permen atau Cookies Daun Krisan Bubuk, Teh bunga Mawar dan Gulali bunga Mawar rasa Jahe dan Original.

Produk hasil dari pengolahan limbah bunga oleh KWT Mitra Veteran Mandiri sudah mulai dijual dan dipasarkan di warung-warung terdekat yang ada disekitar kampung mereka. Produk olahan yang dihasilkan sudah memiliki rasa dan tekstur yang baik namun dalam segi pengemasan harus dilakukan perbaikan supaya mampu memberikan nilai tambah sehingga dapat memenuhi selera konsumen.

\section{KESIMPULAN DAN SARAN}

\section{Kesimpulan}

Program pemberdayaan telah dilaksanakan dengan diawali melalui pembentukan Kelompok Wanita Tani (KWT), sosialisasi, pelatihan, pendampingan, monitoring dan evaluasi. Anggota KWT Mitra Veteran Mandiri sudah mampu memanfaatkan limbah tanaman bunga Krisan menjadi produk olahan yang mempunyai nilai ekonomis, yaitu Teh, Rempeyek/Kripik dan Permen Krisan. Dampak positif yang terjadi adalah anggota KWT Mitra Veteran Mandiri sudah mampu menularkan ketrampilannya kepada anggota masyarakat yang lebih luas, dan mahasiswa Fakultas Pertanian UPN "Veteran" Yogyakarta.

\section{Saran}

Proses Pemberdayaan kepada Masyarakat dengan memanfaatkan hasil maupun limbah dari tanaman lokal yang banyak dibudidayakan sebaiknya dilanjutkan, guna meningkatkan kesejahteraan masyarakat.

\section{DAFTAR PUSTAKA}

Handajaningsih, M dan Wibisono, T. (2009). Pertumbuhan dan pembungaan krisan dengan pemberian abu janjang kelapa sawit sebagai sumber kalium. J. Akta Agrosia, 12 (1) : 8-14.

Madhavi DL, Deshpande SS and Salunke DK. (1996). Antioxidant Food Technology, Toxicological and Health Perspectives. New York : Marcel Dekker, Inc.

Shen S, Sha Y, Deng C, Zhang X, Fu D, and Chen J. (2004). Quality assessment of Flos Chrysanthemi Indici from different growing areas in China by solid- 
Santosa et.al. / Jurnal Dinamika Sosial Ekonomi Vol.20 No.2, Desember 2019

phase microextraction-gas chromatography-mass spectrometry. $J$. Chromatogr. A. 1047: 281-287.

Wang LL, Chen XM, Liu WH, and Wang W. (2006). Comparison of the chemical compositions of the essential oil from Flos Chrysanthemi lndici and its bud. J. Zhejiang Univ. Technol. 34: 389-392.

Wanita, Yeyen Prestyanig, Budi Setyono, dan Deliana P Agriawati. (2015). Krisan (Chrysanthemum Indicum L.) Organik Sebagai Bahan Baku Aneka Pangan Olahan. Yogyakarta : Balai Pengkajian Teknologi Pertanian (BPTP).

Ye Q and Deng CH. (2009). Determination of camphor and borneol in Flos Chrysanthemi Indici by UAE and GC-FID. J. Chromatogr. Sci. 47: 287-290. 